\title{
Capsule Commentary on Gimm et al., Provider Experiences with a Payer-Based PCMH Program
}

\author{
C. Scott Smith, MD \\ University of Washington and Boise VA Medical Center, Boise, USA.
}

$\mathrm{J}$ Gen Intern Med 34(10):2188

DOI: $10.1007 / \mathrm{s} 11606-019-05143-\mathrm{y}$

(c) Society of General Internal Medicine (This is a U.S. government work and not under copyright protection in the U.S.; foreign copyright protection may apply) 2019

$\mathrm{T}$ his cross-sectional study by Gimm et al. ${ }^{1}$ examines provider perceptions of the value of a voluntary, payer-based intervention promoting the Patient-Centered Medical Home (PCMH) model. The five key elements of the intervention were external nurse care coordinators (NCC), individualized care plans, financial incentives, quarterly quality and performance "panel" meetings, and a data portal with cost information. Participants were surveyed by recorded semi-structured focus groups or phone interviews. Thematic analysis of transcript data was performed by a multidisciplinary team. Interventions that supported care coordination (NCC, care plans) were considered valuable. Those aimed at cost control (panel meetings, data portal, incentives) were considered inconvenient and untrustworthy.

Many multisite studies ${ }^{2-4}$ have shown large differences in the success of individual site PCMH adoption. This variability is partly due to the complex nature of these clinics and the PCMH intervention. Process characteristics, such as "adaptive reserve" (capacity for organizational learning and development), can vary widely between clinics. ${ }^{2}$ Adaptive reserve is increased by effective communication and trust, and facilitative leadership. Structural characteristics are also important. Alignment between clinical, operational, and financial goals ${ }^{2}$ and participatory decision making ${ }^{3}$ are both important for successful transformation. As the nation's healthcare moves from "volume to value" in accountable care organizations (ACOs), successful systems "balance mission with margin". 5

For those systems converting to ACOs, especially if they are adopting PCMH as a model, the message is again clear: balance the mission with the margin, involve stakeholders, and maintain transparency. This balance will be contextually different in each clinic and will require design and operational input from all stakeholders (patients, staff, and providers). In this implementation, the rules to provide care coordination only to high-cost outliers and not to those perceived by providers as complex in other ways were a major dissatisfier. Providing cost comparisons and rewards by cross-practice panels was perceived to dilute the value of the information to individual clinics and undermine trustworthiness. Communication styles were perceived as unidirectional. It takes a village to build a great healthcare system, and the whole village should be involved.

Corresponding Author: C. Scott Smith, MD; University of Washington and Boise VA Medical Center, Boise, USA (e-mail: scott. smith2@va.gov).

\section{Compliance with Ethical Standards:}

Conflict of Interest: The author declares that he does not have a conflict of interest.

Publisher's Note: Springer Nature remains neutral with regard to jurisdictional claims in published maps and institutional affiliations.

\section{REFERENCES}

1. Gimm G, Goldberg DG, Ghanem N, Haghighat S, Want J, Hough D, Nichols LM. Provider Experiences with a Payer-Based PCMH Program. J Gen Intern Med. DOI: https://doi.org/10.1007/s11606-019-05005-7

2. Nutting PA, et al. Journey to the patient-centered medical home: A qualitative analysis of the experiences of practices in the National Demonstration Project. Ann Fam Med. 2010; 8(suppl 1):s45-s56.

3. Helfrich CD, et al. Elements of team-based care in a patient-centered medical home are associated with lower burnout among VA primary care employees; J Gen Intern Med. 2014; 29(suppl 2):s659-s666.

4. Friedberg $\mathbf{M W}$, et al. Effects of a medical home and shared savings intervention on quality and utilization of care. JAMA Intern Med. 2015; 175(8): 1362-1368.

5. Millenson ML, et al. Patient-centered care innovations by accountable care organizations: Lessons from the leaders. Healthcare. 2017; doi: https://doi.org/10.1016/j.hjdsi.2018.10.002. [Epub ahead of print] 